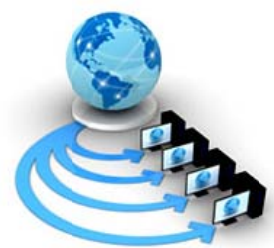

International Journal of Advanced Research in Computer Science

RESEARCH PAPER

\title{
QUEUEING MODEL FOR SOFT HANDOFF ANALYSIS IN CDMA BASED WIRELESS CELLULAR NETWORK
}

\author{
Bhavtosh Awasthi \\ Department of Mathematics \\ JECRC University, Jaipur-303905 \\ Rajasthan, India
}

\author{
Beena Bundela \\ Department of Mathematics \\ JECRC University, Jaipur-303905 \\ Rajasthan, India
}

\begin{abstract}
The most important feature of the mobile network is mobility. Good and continuous service in cellular mobile network can be achieved by using the procedure of handoff (or handover) from one cell to another. Soft handoff is very important feature of cellular Code Division Multiple Access (CDMA) system. In CDMA system, mobile stations (MSs) within a soft handoff region use multiple radio channels and receive their signals from multiple base stations simultaneously and all cells can also share the same frequency. During the handoff procedure, voice and signaling information must be sent to multiple base stations and the mobile station must combine the results. Within the overlapping area (which is developed by the adjacent cells) of cells, a handset can connect to multiple base stations. In this research paper, a new soft handoff scheme for CDMA cellular network is proposed and investigated. Here we introduce the concept of overlap region between adjacent cells and develop an analytical model for soft handoff in CDMA system. In developed soft handoff model, the balking and reneging behaviors of handoff calls have also considered and different performance measures of the soft handoff model have developed.
\end{abstract}

Keywords: Balking, MSC, Base station, CDMA, Overlap region, Soft handoff.

\section{INTRODUCTION}

The rapid growth in the demand for mobile communications has led to an intense research effort to achieve an efficient use of the scarce spectrum allocated for cellular communications system. In cellular network, mobile subscribers (MSs) are provided with calling and data services within a geographical area. The service area is divided into multiple adjacent cells. MSs communicate via radio links to base stations (BSs), one for each cell. When a mobile user moves across a cell boundary[1], the channel in the old base station is released and an idle channel is required in the new base station in which mobile user just going to enter. Such type of phenomenon is known as handoff. Handoff is an important aspect of mobility management in cellular radio system.

Mobility in cellular network is the most important feature. Continuous service can be achieved by using handoff (or handover) procedure from one cell to another. Soft handoff is an important feature of cellular CDMA system, wherein mobile stations (MSs) within a soft handoff region use multiple radio channels and receive their signals from multiple base stations simultaneously. Handoff is the process of changing the channel (time slot, frequency, spreading code, or combination of them) associated with the current mobile user while a call is in progress. It is frequently initiated either by crossing a cell boundary or by deterioration in quality of the signal in the present channel. In mobile network, Handoff is divided into two broad categories: (1) hard handoff and (2) soft handoff. They are also characterized by "break before make" and "make before break" systems. In case of hard handoffs, current channel is released before assigning new channel but in case of soft handoffs, both existing and new channels are used during the handoff process [13]. The process of transferring support of a mobile subscriber from one base station to another base station is known as handoff. Generally Handoff occurs when a call has to be handed off from one cell to another cell as the mobile user moves between cells during calls. Since all cells in CDMA system use the same frequency, it is possible to make the connection to the new cell before leaving the current cell. This is known as a "make-before-break" or "soft" handoff. Soft handoff requires less power, which reduces interference and increases capacity. Cellular communication system requires handoff to provide seamless service for mobile users, moving from one cell to other cell in mobile network. Code division multiple access (CDMA) has received a great deal of attention as a multiple access method for future mobile networks. Its main advantages are higher radios capacity and the capability of flexible data transmission. Lee [1]-[2] presented his overview on mobile communication system and explained different term and future related to mobile communication system and also provided general description of code division multiple access (CDMA) system. Gilhousen et al.[3] discussed on code division techniques for multiple access and developed personal handy phone system. Jabbari et. al.[4] proposed a scheme for a system for personal mobile communication using hard handoff. Khan et al.[5] discussed linear and exponential back off techniques for the uplink common channel packet transmission in wide band CDMA for Poisson arrival process. Greenberg et al.[6] proposed a scheme how to assign distinct number of code channels to each traffic class. Kim and Sung [7] gave different analytical schemes for handoff analysis based on hard handoff in mobile communication system. They also developed an analytical model for soft handoff in CDMA systems by introducing the concept of an overlapping region between adjacent cells and the handoff call attempt rate and the channel holding times 
are derived. Applying these results to a non-prioritized CDMA system, the effects of soft handoff and the mean cell residual time are investigated. Lee et al.[8]-[9] analyzed performance of channel borrowing handoff scheme based on user mobility in CDMA cellular system and also studied the soft-handoff mechanism and compares its performance with the hard handoff. Performability of different models like CTMC, SRN and MRN have analyzed by Trivedi et al. [11]. They calculated different call blocking probability for wireless systems and wireless cellular systems. A new soft handoff scheme in case of CDMA cellular system investigated by Xiaomin et al.[12]. They also estimated the relative mobility of new handoff calls. The different aspect of a cellular geometry in code-division multiple-access (CDMA) systems with soft handoff have described by Xiaomin et al. [13]. They also described some important characteristics of the cellular configuration in soft handoff systems are used to propose a new design of efficient call admission control (CAC) in CDMA systems. Awasthi [14] developed directed retry scheme for cellular radio system having both type of traffic voice and data. He found that the directed retry scheme play an important role to reduce blocking probability of handoff voice calls. The efficient channel allocation and handoff strategies to guarantee continuous service with good Qos (Quality of service) to mobile multimedia users have studied by Nisha et al. [15]. Details on handoff protocols, handoff management issues and handoff decisions are also discussed. Kumar and Purohit [16] discussed the all handoff strategies where it shown that which handoff is required suitable parameters to minimize the handoff. Awasthi [17] analyzed the hand-off performance in personal communication system using splitted rating channel technique. It is observed that from the simulation results that the blocking probability of handoff calls can be reduced by using splitted rating channel and directed retry schemes. Elmadina et al. [18] gave an optimal algorithm for automatic controlling and adapting Global System for Mobile Communication (GSM) power system for handoff. They found that the use of this technique reduce the handoff blocking probability. Kesavan and Palani [19] presented a semi analytical model to study the performance degradation of soft and hard handoff schemes in a downlink CDMA system due to delay in the completion of handoff decisions. A comparison between different handover traffic channel assignment schemes discussed by Adewale et al. [20]. Gohil et al.[21] analyzed the performance of handoff algorithm that use a fixed value of RSS threshold of initiates the handoff process. The concept of overlap region between adjacent cells and develop an analytical model for hard handoff in CDMA system introduced by Awasthi [22]. He also discussed the balking and reneging behaviors of calls and found that the blocking probabilities are decreased as number of channels in a cell or service rate increases.

In this paper, we have developed the mathematical model for soft handoffs in CDMA system to analyze the problem of handoff in cellular radio system. In this model, the balking and reneging behaviors of queued handoff calls also taken into consideration. The system capacity is to be considered finite. We have developed different performance measures like blocking probability of new calls, call incompletion probability, blocking probability of handoff calls etc.

\section{THE SOFT HANDOFF MODEL}

In soft handoff model, the following assumptions are used: The arrival of calls to/from a handset is according to Poisson process. The arrival rate of new calls is $\lambda_{n}$ and the arrival rate of handoff calls is $\lambda_{h}$. The mobile residence time $z_{i}$ in a cell $I$ have an exponential distribution with the density function given by [8] $f_{m}\left(z_{i}\right)=\theta e^{-\theta z_{i}}$

The new call blocking probability is denoted by $p_{n}$ and the probability that a handoff call is blocked is denoted $p_{h}$ The network response time is represented by $t_{n r t}$ and is exponentially distributed with mean $\beta_{T}$. The balking behavior of calls is following exponential distribution with probability of balking $\beta$. The calls may renege according to exponential distribution with reneging parameter $v$. The call holding time tc is exponentially distributed with the mean $1 / \mu$. The number of channels assigned to each cell to serve the calls in a cell is denoted by C. Let $Z_{i}$ be the residence time of the handset at cell. $b_{n}$ Denotes new call blocking probability and $p_{f}$ denotes forced termination probability or the probability that a handoff call is blocked because no channel is available. The call in compilation probability is denoted by $p_{n c}$. $\alpha_{s h}$ is the probability that a soft handoff call is blocked due to the network response time is too long. $P_{i}$ is the steady state probability that there is i customer in the system at any arbitrary point of time.

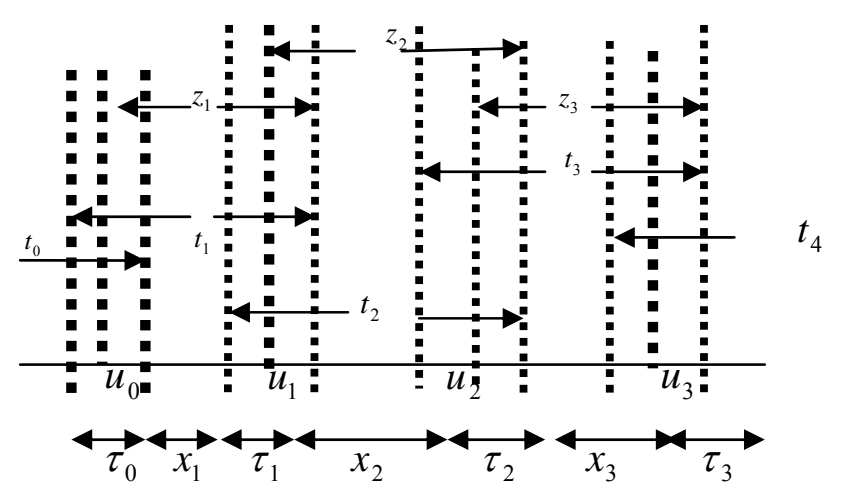

Figure 1 describes the timing diagram for soft handoff model. The notations $t_{i}, \tau_{i}$ and $x_{i}$ represent the time that a handset can receive the signal from cell $i$, time that the handset stay in the overlapping area (or overlay time) and the time that the handset stays in the non overlapping area of cell i respectively. In case of soft handoff, a communicating handset at cell $\mathrm{i}$ utilize one channel during the nonoverlapping period $X_{i}$ and is looking for a second radio link is found at time $u_{i}$, then the channel occupancy time of the handset at cell $\mathrm{i}+1$ is the minimum of $z_{i+1}$ and the remaining call holding time. Assume that $t_{i}$ is exponentially distributed, then by the memory less property, $Z_{i}$ has also 
the same distribution as $t_{i}$ i.e. it exponentially distributed with mean

$$
\frac{1}{u}=\frac{1}{\eta}+\frac{1}{\xi}+\frac{1}{\xi}=\frac{(\xi+2 \eta)}{\xi \eta}
$$

For fixed period of time, the number of calls visited by a mobile user is independent of the handoff schemes and the moving rate of a mobile user in soft handoff is $\theta$.

$\frac{1}{\theta}=\frac{1}{\eta}+\frac{1}{\xi}=\frac{(\eta+\xi)}{\eta \xi}$

Let $\alpha_{s h}$ be the probability that a soft handoff call is blocked because the network response time is too long. In soft handoff scheme, probability of blocking a handoff call due to no radio channel is available is less than the blocking probability of new call. In soft handoff blocking probability of handoff calls due to no radio channel is available is less than new call blocking probability i.e. $p_{h} \prec p_{n}$.

The probability that a handoff call is blocked because no radio channel is available or due to the network response time is too long is given by

$p_{f}=1-\left(1-\alpha_{s h}\right)\left(1-p_{h}\right)$

The handoff calls arrival rate in a cell is given by

$$
\lambda_{h}=\frac{\theta\left(1-p_{n}\right) \lambda_{n}}{\mu+\theta\left[1-\left(1-\alpha_{s h}\right)\left(1-p_{h}\right)\right]}
$$

The call incompletion probability is derived as

$$
p_{n c}=p_{n}+\frac{\theta\left(1-p_{n}\right)\left[1-\left(1-\alpha_{s h}\right)\left(1-p_{h}\right)\right]}{\mu+\theta\left[1-\left(1-\alpha_{s h}\right)\left(1-p_{h}\right)\right]}
$$

\section{MATHEMATICAL ANALYSIS}

The soft handoff scheme for a cellular mobile system with finite buffering capacity using $\mathrm{M} / \mathrm{M} / \mathrm{C} / \mathrm{K}$ finite capacity model has been developed. $\mathrm{C}$ channels are available in each cell of the cellular radio system for serving for handover and new calls. The occupancy time of a channel is exponentially distributed with rate $(\mu+\theta)$. The net traffic to the system is $\left(\lambda_{n}+\lambda_{h}\right)$. In each cell two types of calls are arriving: (1) new calls, and (2) handoff calls. The balking behaviors of calls are also considered. We assume that a handset can connect up to two radio links in a CDMA system.

The soft handoff scheme has been modeled according to Markov process with state $T(n)$, where $n \geq 0$ represents the number of busy channels in queueing system. Transition rate diagram of Markov Process has been given in figure 2. When the process is in state $T(n)$ for $0 \leq_{n} \prec C, n$ channels are busy. The effective call traffic to a cell at the state $\mathrm{T}(\mathrm{n})$ is $\left(\lambda_{n}+\lambda_{h}\right)$ and the process moves from states $\mathrm{T}(\mathrm{n})$ to $\mathrm{T}(\mathrm{n}+1)$ with this rate. Since a busy channel is released with the rate $(\mu+w)$ and the process moves from state $\mathrm{T}(\mathrm{n})$ to $\mathrm{S}(\mathrm{n}-1)$ for $0 \prec_{\mathrm{n}} \leq \mathrm{C}$ with the rate $\mathrm{n}(\mu+w)$. When the process is in state $\mathrm{T}(\mathrm{C}+\mathrm{j})$ where $\mathrm{j} \geq 0$, all the channels are busy and $\mathrm{j}$ handoff calls are looking for the second links. When a call arrives at state $\mathrm{T}(\mathrm{C}+\mathrm{j})$, then call is dropped if it is a new call. On the other hand, if the call is a handoff call, then it is trying to connect to the second link before it leaves the overlay area during this a call may be walk from the system. Thus the process moves from state $\mathrm{T}(\mathrm{C}+\mathrm{j})$ to state $\mathrm{T}(\mathrm{C}+\mathrm{j}+1)$ with rate $(1-\beta) \lambda_{h}$ for $\mathrm{j} \geq 0$. Since all channels are busy, the first completion among the $\mathrm{C}$ connected calls releases its channel with rate $\xi$. For those $\mathrm{j}$ handoff calls that look for the second links, before the second links are available, the calls may leave the system in three cases:

(1) The handset leaves the overlapping area with rate $\xi$ and is forced terminated.

(2) The call is completed with rate $\mu$.

(3) The call may be reneged with rate $v$.

Thus the first such call leaves the system with the rate $j(\mu+\xi+v)$ and the process moves from the state $\mathrm{T}(\mathrm{C}+\mathrm{j})$ to state $\mathrm{T}(\mathrm{C}+\mathrm{j}+1)$ with rate $[C(\mu+w)+j(\mu+\xi+v)]$ for $\mathrm{j} \succ 0$.

Let $\pi_{i}$ be the steady state probability for T(i). Then

$$
\pi_{i}=\left\{\begin{array}{l}
\frac{\left(\lambda_{n}+\lambda_{h}\right)^{i}}{! i(\mu+\omega)^{i}} \pi_{0}, \quad 0 \leq i \leq C \\
\frac{\left(\lambda_{n}+\lambda_{h}\right)^{c}\left\{(1-\beta) \lambda_{h}\right\}^{i-C}}{! C(\mu+\omega)^{c} \prod_{j=1}^{K-C}[C(\mu+\omega)+j(\mu+\xi+v)]} \pi_{0}, \quad C+1 \leq i \leq K
\end{array}\right.
$$

Where $P_{0}$ can be obtained by using normalization condition

$$
\begin{gathered}
\sum_{i=0}^{K} \pi_{i}=1 \\
\pi_{0}=\left\{\sum_{i>C+1}^{K} \frac{\left(\lambda_{n}+\lambda_{h}\right)^{C}\left((1-\beta) \lambda_{h}\right)^{i-C}}{C !(\mu+\omega)^{C} \prod_{j=1}^{K-C}[C(\mu+\omega)+j(\mu+\xi+v)]}+\sum_{i=1}^{c} \frac{\left(\lambda_{n}+\lambda_{h}\right)^{i}}{i !(\mu+w)^{i}}\right\}^{-1}
\end{gathered}
$$

By using steady state probability given in (4), we calculate various blocking probabilities as

Blocking probability for new call is given by

$$
p_{n}=\sum_{i=C}^{K} \pi_{i}
$$

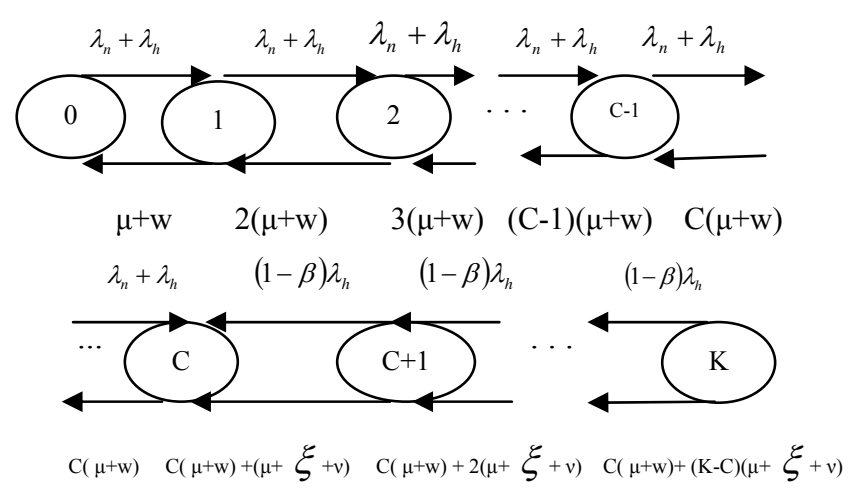

(Fig. 2: Transition rate diagram for $M \backslash M \backslash C \backslash K$ System) 
Suppose that a handoff call $C_{t}$ arrives at time $\mathrm{t}$ when the cell is in state $\mathrm{T}(\mathrm{i})(\mathrm{i}=\mathrm{C}+\mathrm{j})$ and the call leaves the overlapping area at time $\mathrm{t}+\tau$. Let $\tau_{c}$ be the remaining call holding time of $C_{t}$ at $\mathrm{t} i$. e. the call will be completed at time $\mathrm{t}+\tau_{c}$. Consider $\mathrm{c}+\mathrm{j}$ outstanding calls that arrive at the cell earlier than $C_{t}$. Let among these $\mathrm{C}+\mathrm{j}$ calls, the first call leaves the system (either completes, expires or leaves the cell) at time $\mathrm{t}+t_{j}$.

Then the density function for $t_{j}$ is

$$
f_{j}\left(t_{j}\right)=[C(\mu+w)+j(\mu+\xi+v)] e^{-[C(\mu+w)+j(\mu+\xi+v)] t_{j}}
$$

If $t_{j} \prec \tau$, then at time $\mathrm{t}+t_{j}, C_{t}$ sees $\mathrm{C}$ handsets in conversations and $\mathrm{j}-1$ handoff calls looking for the second links. Now consider the first call that leaves the system among these $\mathrm{C}+\mathrm{j}-1$ calls (excluding $C_{t}$ ). Let the call leaves the system at time $\mathrm{t}+t_{j}+t_{j-1}$.

Assume $T_{j}=t_{0}+t_{1}+t_{2}+\ldots t_{j}$

The probability that the $C_{t}$ is blocked is given by

$$
\begin{aligned}
& P_{r}\left[\tau \prec T_{j} \text { and } \tau \succ \tau_{c} / S(C+j)\right]= \\
& \int_{t_{j}=0}^{\infty}---\int_{t_{0}=0}^{\infty} \int_{\tau=0}^{T_{j}} \int_{\tau_{c}=0}^{\tau} \xi e^{-\xi \tau} \mu e^{-\mu \tau_{c}}\left[\prod_{k=0}^{j} f_{k}\left(t_{k}\right)\right] d \tau_{c} d \tau d t_{1} . . d t_{j} \\
& =\frac{(j+1) \xi}{C(\mu+\omega)+(j+1)(\mu+\xi+v)}
\end{aligned}
$$

The probability that no radio resource is available for a handoff call is

$$
\begin{aligned}
p_{h} & =\sum_{j=0}^{K-C} P\left[\tau<T_{j} \text { and } \tau>\tau_{c} / S(C+j)\right] \pi_{C+j} \\
& =\sum_{j=0}^{K-C} \frac{(j+1) \gamma \pi_{C+j}}{C(\mu+\omega)+(j+1)(\mu+\xi+v)}
\end{aligned}
$$

\section{DERIVATION FOR $\alpha_{s}$}

Let $\tau_{\mathrm{i}}{ }^{*}$ be the period between the handset connects to the cell and when the handset leaves the overlapping area. The probability that a soft handoff call is blocked because of too long network response time is given by

$$
\begin{aligned}
\alpha_{s h} & \left.=P_{r} \mid t_{n r t}>\tau_{i}^{*}\right\rfloor \\
& =\int_{\tau_{i}^{*}=0}^{\infty} \int_{t_{n r t}}^{\infty} \beta_{T} e^{-\beta_{T} t_{n r t}} \xi e^{-\xi \tau_{i}^{*}} d t_{n r t} d \tau_{i}^{*} \\
& =\frac{\xi}{\xi+\beta_{T}}
\end{aligned}
$$

\section{FURTHER WORK}

We can analyze using more than two base stations involved in soft hand to see the effect on performance of communication Network. Combination of other schemes like channel borrowing during handoff process can be analyzed for QoS parameters.

\section{DISCUSSIONS}

We derived mathematical model to analyze the problem of handoffs in CDMA (Code Division Multiple Access) network. Balking and reneging behaviors of queued handoff calls are considered in this chapter and only voice traffic of new and handoff calls considered. Formulae for different type blocking probabilities have been developed and effect of Balking and reneging behaviors of calls on performance indices are summarized.

\section{REFERENCES}

[1] W. C. Y. Lee," Mobile cellular telecommunication system," New York: Mc Graw Hill, 1989.

[2] W. C. Y. Lee," Overview of cellular CDMA," IEEE Trans. Veh. Technol., Vol. 40, No. 2, pp. 291-302, 1989.

[3] K. S. Gilhousen, I. M. Jacobs, R. Padovni, A. J. Viterbi, L. A. Weaver, and wheatley, "On the capacity of a cellular CDMA system," IEEE Trans. Veh. Technol., Vol. 40, No. 2, pp. 303-312, 1991.

[4] B. Jabbari, G. Colombo, A. Nakajima, and J. Kulkarni,,'Network uses for wireless communications," IEEE Commun., Mag., Jan. 1995.

[5] F. Khan, C. Roobol, and J. Larsson,"Performance of a common channel packet access in WCDMA," IEEE Proc. Int. Symp. Pers.," Indore Mobile Radio Commun. (PIMRC), Vol. 1, pp. 198-202, Sept. 1998.

[6] A. G. Grunberg,R. Srikant, and W. Whitt," Resource sharing for book ahead and instantaneous request calls, IEEE / ACM Trans. Networking, vol. 7, pp. 10-22, 1999.

[7] D. K. Kim, and D. K. Sung, "Characterization of soft handoff in CDMA systems," IEEE Trans. Veh. Technol., Vol. 48, No. 4, pp. 1195-1202, 1999.

[8] D. J. Lee, and D. H. Cho," Performance analysis of channel borrowing handoff scheme based on user mobility in CDMA cellular system," IEEE, Trans Veh. Technol., Vol. 49, pp. 2276-2285, 2000.

[9] Y. B. Lin, and A. C. Pang,"Comparing soft and the hard handoffs, IEEE," Trans. Veh. Technol., Vol. 49,no. 3, pp. 792-798, 2000.

[10] Y. B. Lin, "Impact of PCS handoff response time," IEEE Commun. Lett., Vol. 1, No. 6, pp.160-62, 1997.

[11] K. S. Trivedi, M. Xiaomin, and S. Dharmaraja ,Performability modelling of wireless communication systems," Int. J. Commun. Syst., Vol. 16, pp. 561-577, 2003.

[12] M. Xiaomin, Y. Liu, and K. S. Trivedi,” Design and Performance Analysis of a New Soft Handoff Scheme for CDMA Cellular Systems," IEEE TRANSACTIONS ON VEHICULAR TECHNOLOGY, Vol. 55, no. 5, pp. 1603-1612, 2006.

[13] M. Xiaomin, Y. Cao, Y. Liu, and K. S. Trivedi, "Modeling and Performance Analysis for Soft Handoff Schemes in CDMA Cellular Systems," IEEE TRANSACTIONS ON VEHICULAR TECHNOLOGY, Vol. 55, no. 2, pp. 670-679, 2006. 
[14] B. Awasthi, "Performance Evaluation of Cellular Radio System with Directed Retry," IOSR Journal of Mathematics (IOSR-JM), Vol. 7, Issue 6, pp.33-39, 2013.

[15] Nisha, S. Kumar, and J. Bhatnagar, "Handoff Strategies in Cellular System," International Journal of New Trends in Electronics and Communication,,Vol.1, Issue. 2, pp. 22-28, 2013.

[16] A. Kumar, and H. Purohit, "A COMPARATIVE STUDY OF DIFFERENT TYPES OF HANDOFF STRATEGIES IN CELLULAR SYSTEMS," International Journal of Advanced Research in Computer and Communication Engineering, Vol. 2, Issue 11,pp. 4278-4287, 2013.

[17] B. Awasthi,'Hand Off Problem Analysis In Personal Communication System Using Splitted-Rating Channel Technique," International Journal of Scientific \& Technology Research, Vol. 3, Issue 1, pp. 103-108, 2014.

[18] Elmadina N. N., Abdalrahman R., Abudia M. and Bihary N.,"Optimal Performance of Algorithm Handoff in Wireless Mobile Networks," International Journal of
Computer Science and Telecommunications, Vol. 6, Issue 5, pp. 14-18, 2015.

[19] Kesavan G. and Palani S.,"Performance Analysis of Channel-barrowing Hand-off Scheme in CDMA Cellular Systems," Research Journal of Applied Sciences, Engineering and Technology Vol. 9, no. 6, pp. 466-470, 2015.

[20] A. A. Adewale, S. N. John, R. Emmanuel, and E. R. Adagunodo," Performance Comparison of Dynamic Guard Channel Assignment with Buffered Prioritized Scheme for Mobile WiMAX Network," Vol. 1, June 29 - July 1, 2016, London, U.K.

[21] Z. M. Gohil, D. N. Khandhar, and K. M. Pattani, "Implement \& Analysis of RSS Threshold based Vertical handoff Decision Algorithm for LTE \& WLAN," Int. J. of Innovative Res. in Comp. and Commu. Engg., Vol. 5, Issue 1, pp. 311-317, 2017.

[22] B. Awasthi, " Handoff Analysis in CDMA Based Wireless Cellular Network using Hard Handoff Model," Journal of Computer and Mathematical Sciences, Vol.8, no. 12, pp. 739-749, 2017. 